\title{
Effect of temperature switchover on the degradation of antibiotic chloramphenicol by biocathode bioelectrochemical system
}

\author{
Deyong Kong ${ }^{1}$, Bin Liang ${ }^{1}$, Duu-Jong Lee ${ }^{1}$, Aijie Wang ${ }^{1,2, *}$, Nanqi Ren $^{1, *}$ \\ 1. State Key Laboratory of Urban Water Resource and Environment, School of Municipal and Environmental Engineering, \\ Harbin Institute of Technology, Harbin 150090, China. E-mail: kongdeyong0453@163.com \\ 2. Key laboratory of Environmental Biotechnology, Research Center for Eco-Environmental Sciences, Chinese Academy of Sciences, \\ Beijing 100085, China
}

\section{A R T I C L E I N F O}

\section{Article history:}

Received 23 September 2013

Revised 25 November 2013

Accepted 7 March 2014

Available online 23 June 2014

Keywords:

Chloramphenicol degradation

Biocathode

Dechloridation

Temperature switchover

\begin{abstract}
A B S T R A C T
Exposure to chloramphenicol (CAP), a chlorinated nitroaromatic antibiotic, can induce CAP-resistant bacteria/genes in diverse environments. A biocathode bioelectrochemical system (BES) was applied to reduce CAP under switched operational temperatures. When switching from 25 to $10^{\circ} \mathrm{C}$, the CAP reduction rate $\left(k_{\mathrm{CAP}}\right)$ and the maximum amount of the dechlorinated reduced amine product (AMCl, with no antibacterial activity) by the biocathode communities were both markedly decreased. The acetate and ethanol yield from cathodophilic microbial glucose fermentation (with release of electrons) was also reduced. Formation of the product $\mathrm{AMCl}$ was enhanced by the biocathode dechloridation reaction compared with that produced from pure electrochemical or microbial dechloridation processes. The electrochemical and morphological analyses of cathode biofilms demonstrated that some cathodophilic microbes could adapt to low temperature and play a key role in CAP degradation. The resilient biocathode BES has a potential for the treatment of CAP-containing wastewater in temperature fluctuating environments.
\end{abstract}

(C) 2014 The Research Center for Eco-Environmental Sciences, Chinese Academy of Sciences.

Published by Elsevier B.V.

\section{Introduction}

Antibiotics are emerging environmental micro-pollutants that cannot be completely removed by conventional wastewater treatment processes. Sewage treatment plants are important point sources of antibiotic entry into the environment (Leung et al., 2012; Zhang and Li, 2011). Exposure to antibiotic substances can result in evolution of multidrug-resistant bacteria and novel antibiotic-resistant genes, which has enormous ramifications for human health and has attracted global attention (Andam et al., 2011; Davies and Davies, 2010; Le-Minh et al., 2010; Zhang et al., 2009).
The chlorinated nitroaromatic antibiotic chloramphenicol (CAP) is an effective broad spectrum antibiotic that has been widely used since 1950's. Owing to its fatal toxic effects in humans (e.g., aplastic anemia, potential carcinogenicity and genotoxicity) (Feder et al., 1981; Martelli et al., 1991), CAP has been banned by many countries for use in food-producing animals. However, CAP is still widely used in low-income countries as it is inexpensive and readily available. Trace levels of CAP (ng to $\mu \mathrm{g}$ level) and novel CAP-resistant bacteria/genes are frequently detected in diverse ecosystems (Leung et al., 2012; Li et al., 2013; Liang et al., 2013; Parsley et al., 2010; Xi et al., 2009; Zhang and Li, 2011; Zhang et al., 2009). Thus, a CAP

\footnotetext{
* Corresponding authors. E-mail: waj0578@hit.edu.cn (Aijie Wang), rnq@hit.edu.cn (Nanqi Ren).
} 
degradation system with high efficiency is needed to decrease the possibility of evolution of CAP-resistant bacteria/genes in the environment.

The bioelectrochemical system (BES) has been developed for the enhanced removal of recalcitrant pollutants. The BES has been applied for cathodic reduction of diverse pollutants (Huang et al., 2011; Rosenbaum et al., 2011), particularly for the reduction of nitroaromatic pollutants (Li et al., 2010; Liang et al., 2013, 2014; Mu et al., 2009; Shen et al., 2012; Sun et al., 2012; Wang et al., 2011, 2012). Bioelectrochemical degradation of CAP by biocathodes and abiotic cathodes was recently studied (Liang et al., 2013; Sun et al., 2013). In general, environmental temperatures vary daily, especially in winter, or at high latitudes and in hilly regions. However, the effects of temperature shift, e.g., dropping $15^{\circ} \mathrm{C}$, on the efficiency of biocathodic CAP degradation have not yet been studied. Low temperature would lower rates of conventional anaerobic biological conversion processes (Lettinga et al., 2001). However, the BES could efficiently produce current (Liu et al., 2012a; Michie et al., 2011) and hydrogen (Lu et al., 2011, 2012) at low temperatures $\left(4-15^{\circ} \mathrm{C}\right)$. Thus, incorporation of an abiotic cathode $\mathrm{BES}$ in the conventional anaerobic biological reduction process may be a promising process for handling CAP-containing wastewaters with fluctuating ambient temperatures.

This study investigated the chemical kinetics of CAP degradation and product formation subject to an operational temperature switch from 25 to $10^{\circ} \mathrm{C}$, with abiotic cathode and open-circuit biocathode BES tests as controls. The cathodophilic microbial role in the CAP transformation was revealed by cyclic voltammetry (CV), electrochemical impedance spectroscopy (EIS) and live/dead staining confocal laser scanning microscope (CLSM) analysis. The results have proved the effectiveness of reductive degradation of CAP by the biocathode BES with changing operational temperatures.

\section{Materials and methods}

\subsection{BES reactor setup}

The BES reactors were constructed from two equal-volume Lexan cubic chambers $(4 \times 4 \times 3 \mathrm{~cm})$ with a cylindrical cavity ( $3 \mathrm{~cm}$ in diameter and $4 \mathrm{~cm}$ in length). The internal volume for each chamber was $28 \mathrm{~mL}$ and they were separated with a pretreated cation exchange membrane (Ultrex CMI-7000, Membranes International, Ringwood, NJ, USA). Electrodes were made of graphite fiber brush $(2.5 \mathrm{~cm}$ in diameter and $2.5 \mathrm{~cm}$ in length, TOHO TENAX Co., Ltd., Tokyo, Japan). A high-precision resistor $(10 \Omega)$ with external power $(0.5 \mathrm{~V})$ in series was employed for the connection. The saturated calomel electrode (SCE) (SCE, $0.247 \mathrm{~V}$ Us. standard hydrogen electrode (SHE) model-217, Shanghai Precise. Sci. Instrument Co., Ltd., Shanghai, China) was employed as the reference electrode to measure the cathode potential. All of the potential data reported herein are against SHE.

\subsection{Microbial inoculum and BES tests}

Enrichment of the CAP-reducing consortium was carried out according to Liang et al. (2013). Activated sludge obtained from Taiping Wastewater Treatment Plant (Harbin, China) was used as inoculum. The CAP-reducing microbial consortium was the seed for cathode biofilm development in the BES at $25^{\circ} \mathrm{C}$ (Liang et al., 2013). Six BES reactors with mature cathode biofilms were operated for a total of six batch-fed cycles (Cooling Incubator, BI-250A, STIK, Shanghai, China) to collect data for the biocathode mode at $25^{\circ} \mathrm{C}$ (referred to as the

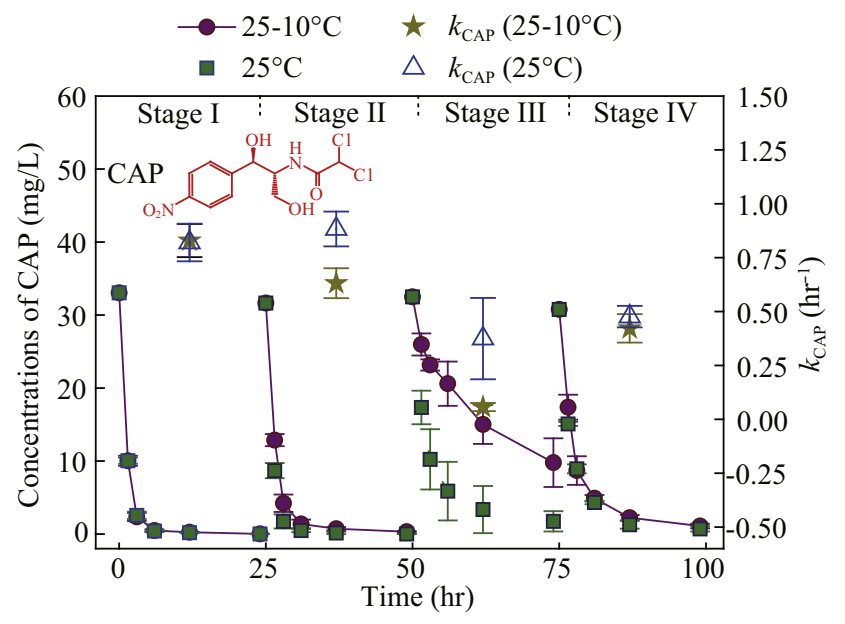

Fig. 1 - Dynamic characterization of CAP degradation in bioelectrochemical system under different operational modes. Stage I: six biocathode reactors (divided into two groups) performed at $25^{\circ} \mathrm{C}$; stage II: biocathode reactors performed at 25 us. $10^{\circ} \mathrm{C}$; stage III: open-circuit biocathode reactors performed at 25 vs. $10^{\circ} \mathrm{C}$; stage IV: abiotic cathode reactors performed at 25 us. $10^{\circ} \mathrm{C}$ as controls.

RT-biocathode). Subsequently, three reactors were switched to low temperature $\left(10^{\circ} \mathrm{C}\right)$ (LT-biocathode in short) (Cooling Incubator, BI-250A, STIK, Shanghai, China) for another six cycles to collect operational data at $10^{\circ} \mathrm{C}$. The remaining three reactors were kept at $25^{\circ} \mathrm{C}$ for another six cycles (a total of 12 cycles for $25^{\circ} \mathrm{C}$ mode). In biocathode mode, CAP $(30 \mathrm{mg} / \mathrm{L})$, glucose $(600 \mathrm{mg} / \mathrm{L})$ and the cathode electrode were the cathode electron acceptor, the intracellular electron donor and extracellular electron donor for cathodophilic microbes, respectively. When the electrical circuit of the biocathode BES was disconnected, the open-circuit biocathode test was performed (with only microbial activities with glucose as intracellular electron donor). To collect abiotic CAP degradation data, two other BES reactors with abiotic cathodes were tested for three cycles at 25 and $10^{\circ} \mathrm{C}$, respectively. Medium compositions and preparation process for the catholyte and anolyte were as previously described (Liang et al., 2013; Wang et al., 2013).

\subsection{Chemicals and analytical methods}

CAP (>98\% purity) and high performance liquid chromatography (HPLC) grade methanol were purchased from Sigma-Aldrich (St. Louis, MO, USA). Other chemicals used in this study were of analytical grade.

Effluent samples taken from the cathode chamber (at 1.5, 3, 6, 12 and $24 \mathrm{hr}$ ) were filtered through a $0.45 \mu \mathrm{m}$ filter before chemical analysis. The concentrations of CAP and the products of CAP transformation were measured using a reverse-phase HPLC (model-2695, Waters, Milford, MA, USA) equipped with a

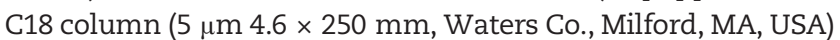
with UV detection at $250 \mathrm{~nm}$ for $\mathrm{AMCl} 2$ and $\mathrm{AMCl}, 275 \mathrm{~nm}$ for CAP and CAP-acetyl, and $310 \mathrm{~nm}$ for the NO intermediate, respectively. The mobile phase was methanol/ $\mathrm{H}_{2} \mathrm{O}(55: 45 ; \mathrm{V} / \mathrm{V})$ at a flow rate of $0.8 \mathrm{~mL} / \mathrm{min}$ at $30^{\circ} \mathrm{C}$ (Liang et al., 2013). To identify 

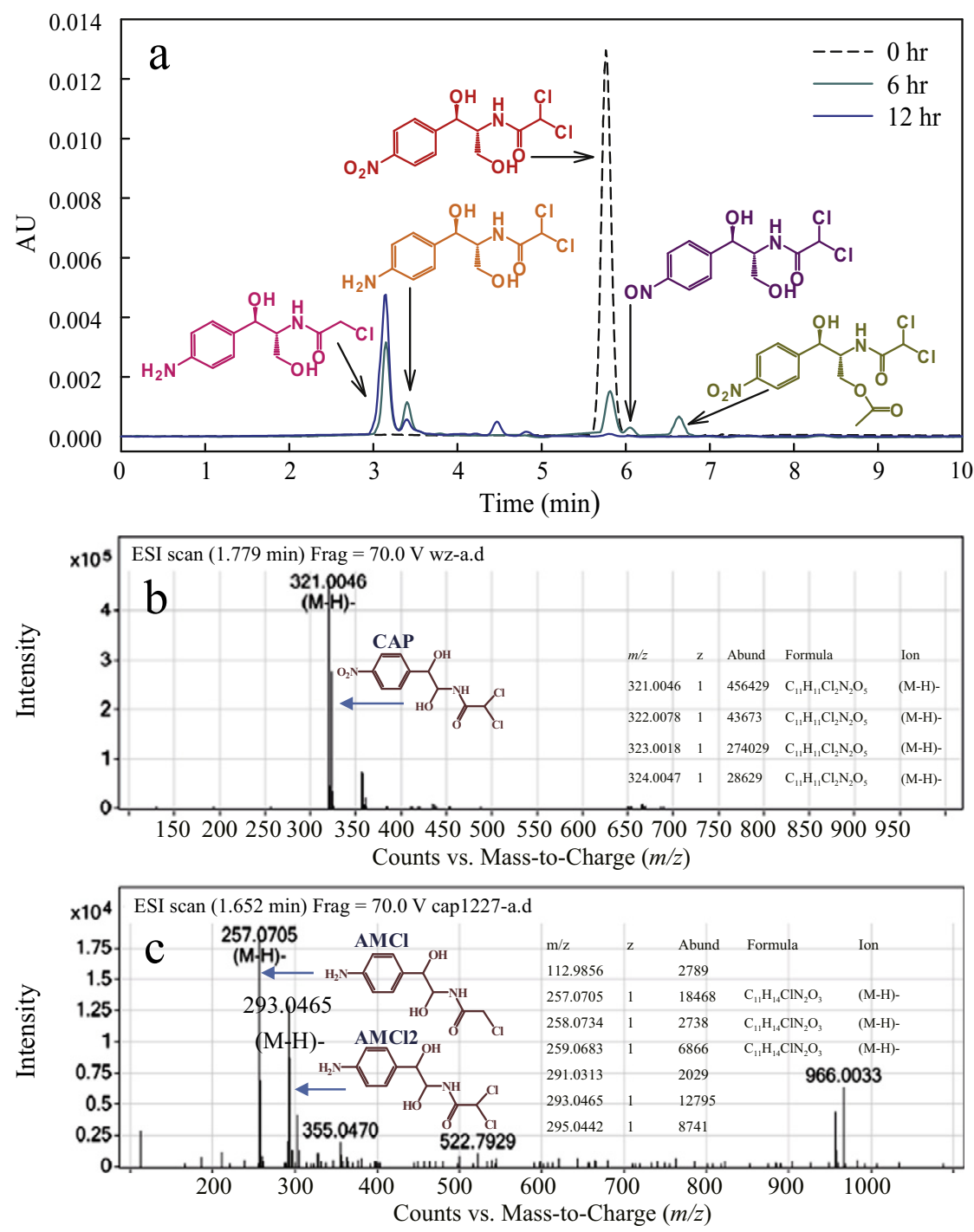

Fig. 2 - HPLC (a) and LC-QTOFMS (b and c) chromatograms of the cathode influent and effluent samples. CAP, AMCl and AMCl2 were identified according to their theoretical molecular weight and characteristic chlorine atom isotope clusters.

the products during CAP transformation, reversed phase liquid chromatography (model-1200, Agilent, Santa Clara, CA, USA) with quadrupole time-of-flight mass spectrometry (QTOFMS) (model-6520, Agilent, Santa Clara, CA, USA) detection in the negative ion mode was carried out on an Agilent Zorbax XDB C18 column (Agilent, Santa Clara, CA, USA) $(1.8 \mu \mathrm{m} ; 2.1 \times 100 \mathrm{~mm})$ with methanol/ $\mathrm{H}_{2} \mathrm{O}(55: 45 ; \mathrm{V} / \mathrm{V})$ as the mobile phase at a flow rate of $0.15 \mathrm{~mL} / \mathrm{min}$ and UV detection at $250 \mathrm{~nm}$ (Liang et al., 2013).

Glucose in the biocathode effluent (at $6 \mathrm{hr}$ ) was determined by the phenol-sulfuric acid method (Herbert et al., 1971). Volatile fatty acids (VFAs) and ethanol in the biocathode effluent were analyzed using a gas chromatograph (Agilent, 4890D; J\&W Scientific, Folsom, CA, USA) with a flame ionization detector (FID) and an appropriate column (19095N-123 HPINNOWAX, $30 \mathrm{~m} \times 0.53 \mathrm{~mm} \times 1.00 \mu \mathrm{m}$, J\&W Scientific, Folsom, CA, USA) using nitrogen as carrier gas (Liu et al., 2012b).

The electric current (I) and CAP reduction efficiency $\left(\mathrm{Er}_{\mathrm{CAP}}, \%\right)$ were calculated based on the difference between influent and effluent CAP concentrations (Wang et al., 2011). The kinetics of CAP transformation was assumed to follow the first-order reaction model $C=C_{0} \times \mathrm{e}^{-k t}$ where, $C(\mathrm{mg} / \mathrm{L})$ represents the CAP concentration at time $t(\mathrm{hr})$, and $C_{0}(\mathrm{mg} / \mathrm{L})$ is the initial CAP concentration (30 mg/L) (Liang et al., 2013). The rate constant $k\left(\mathrm{hr}^{-1}\right)$ calculation and statistical analysis (two-tailed unpaired t-test) were performed by SigmaPlot v.11.0 software (Systat Software Inc., Chicago, IL, USA).

\subsection{CV and EIS analyses}

The CV tests were performed using an electrochemical workstation (WMPG1000K8 Multichannel Potentiostat, WonATech Co., Ltd., Seoul, South Korea) equipped with a three-electrode system. The cathode/biocathode and the anode of the BES were used as the working and counter electrode, respectively. The SCE was the reference electrode. Cyclic voltammograms were recorded with the scan rate of $5 \mathrm{mV} / \mathrm{sec}$.

The EIS tests were carried out over a frequency range of 0.01 to $10^{5} \mathrm{~Hz}$ (Kong et al., 2013) and amplitude of $5 \mathrm{mV}$ (WMPG1000K8 Multichannel Potentiostat, WonATech Co., Ltd., Seoul, South Korea) for the analysis of the polarization internal 
resistance of the abiotic cathode and biocathode BES under different operational modes. Concentrations of CAP and glucose were 30 and $600 \mathrm{mg} / \mathrm{L}$, respectively, when used in the CV and EIS analyses at $25^{\circ} \mathrm{C}$.

\subsection{Microscopy analysis}

The immobilization and morphology observation of RTbiocathode and LT-biocathode biofilms (both had two biological replicates) were carried out by scanning electron microscopy (SEM) (HELIOS Nanolab 600i, Hillsboro, OR, USA) at $20 \mathrm{kV}$ acceleration voltage according to Xie et al. (2011).

RT-biocathode and LT-biocathode biofilms (both had two biological replicates) were stained with the LIVE/DEAD BacLight Bacterial Viability Kit (L7012) (Molecular Probes, Invitrogen, Carlsbad, CA, USA) according to the manufacturer's instructions and then examined using CLSM (CARL ZEISS LSM 700, Oberkochen, Germany).

\section{Results and discussion}

\subsection{Bioelectrochemical degradation of CAP}

The CAP reduction rates $\left(k_{\mathrm{CAP}}\right)$ under four different operational modes were compared. In stage I (biocathode; $25^{\circ} \mathrm{C}$ ), the $k_{\mathrm{CAP}}$ for all BES biocathodes was close $(p=0.750, n=18)$, confirming the consistency of the performance of the six biocathode reactors. When switching the operational temperature of the three test reactors from 25 to $10^{\circ} \mathrm{C}$ (stage II, LT-biocathode, $10^{\circ} \mathrm{C}$ us. RT-biocathode, $25^{\circ} \mathrm{C}$ ), the $k_{\mathrm{CAP}}$ of the LT-biocathode was markedly decreased $(p<0.001, n=18)$ (Fig. 1), suggesting strong temperature effects on CAP reduction activity by the cathodophilic microbes. However, within $24 \mathrm{hr}$ of testing, the $\mathrm{Er}_{\mathrm{CAP}}$ of the LT-biocathode $(98.94 \% \pm 0.66 \%)$ was close to that of the RT-biocathode $(99.98 \% \pm 0.10 \%)$. When the circuit of the biocathode was disconnected (stage III, opencircuit biocathode with only microbial activity), the open-circuit RT-biocathode $\left(\operatorname{Er}_{\mathrm{CAP}}\right.$ of $94.65 \% \pm 4.26 \%$ at $24 \mathrm{hr}$ ) had higher $k_{\mathrm{CAP}}$ $(p=0.044, n=3)$ and $\operatorname{Er}_{\mathrm{CAP}}(p=0.018, n=3)$ than those of the open-circuit LT-biocathode $\left(\operatorname{Er}_{\mathrm{CAP}}\right.$ of $69.90 \% \pm 10.25 \%$ at $24 \mathrm{hr}$ ) (Fig. 1). Additionally, decrease in operational temperature had no significant effects on $k_{\mathrm{CAP}}$ or $\operatorname{Er}_{\mathrm{CAP}}(>95 \%)$ of the abiotic cathode BES (stage IV) $(p=0.319$ or $p=0.195, n=3)$. This occurrence suggested that anodophilic microbes enriched at $25^{\circ} \mathrm{C}$ could efficiently generate electrons in the anode and together with the applied external voltage of $0.5 \mathrm{~V}$ for CAP degradation at $10^{\circ} \mathrm{C}$. The $k_{\mathrm{CAP}}$ of the open-circuit LT-biocathode was lower than that of the LT-biocathode and of the abiotic cathode (both at $p<0.001$ level). Notably, the LT-biocathode $(0.632 \pm$ $0.069)$ had larger $k_{\mathrm{CAP}}$ than that of the abiotic cathode $\left(10^{\circ} \mathrm{C}\right)$ $(0.422 \pm 0.066)(p<0.001)$ (Fig. 1). The cathodophilic microbes present could adapt to low temperature stress for CAP degradation.
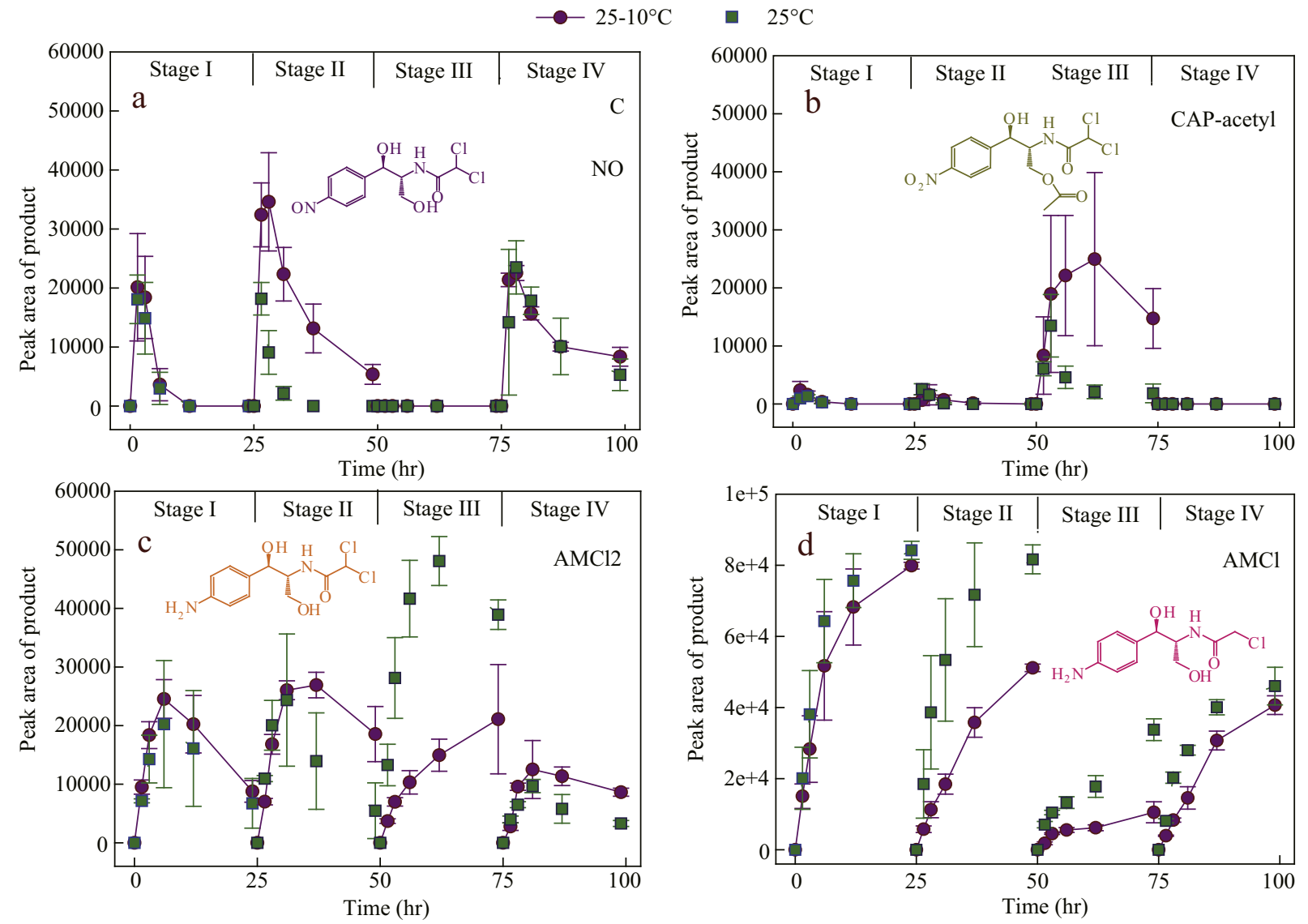

Fig. 3 - Dynamic characterization of four major CAP degradation product formation (AMCl2, AMCl, NO and CAP-acetyl) under different operational modes. 

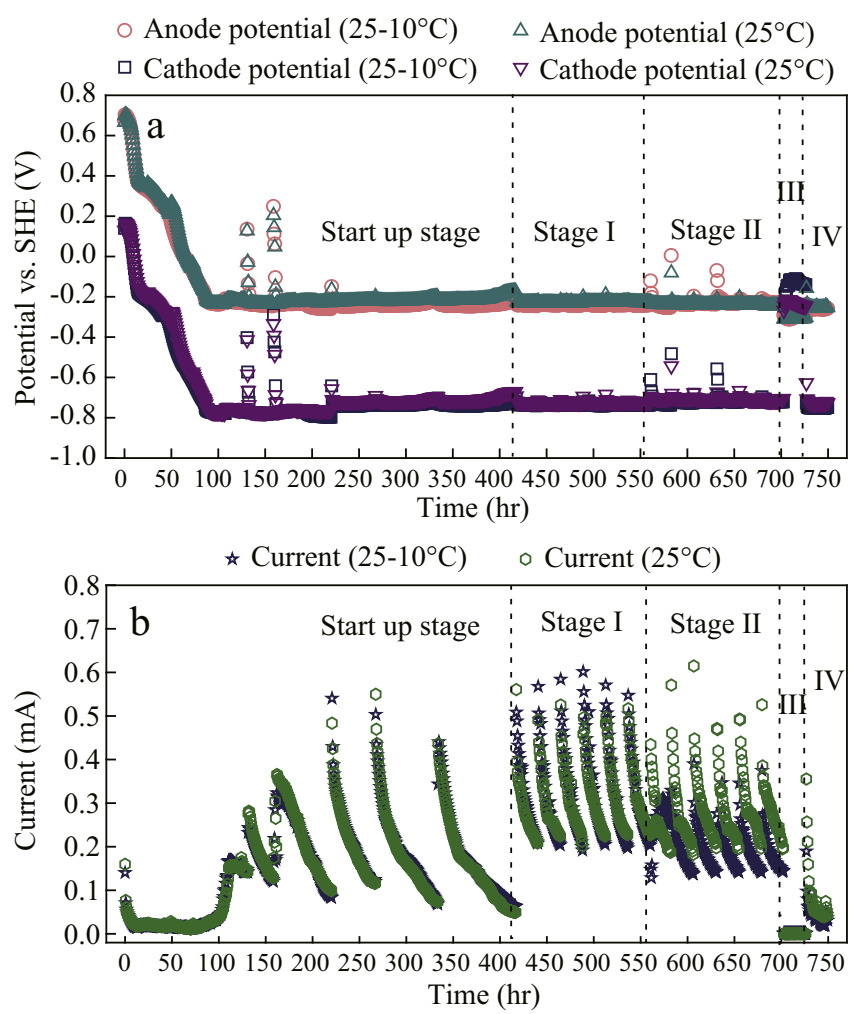

Fig. 4 - Anode and cathode potential us. SHE (a) as well as the reaction current of CAP degradation (b) for the startup stage and continuous fourteen batch-fed cycles in BES reactors under different operational modes.

\subsection{Products of CAP degradation}

The identification of CAP degradation products (AMCl2: reduced amine product; AMCl: dechlorinated AMCl2; NO: nitroso intermediate; CAP-acetyl: acetylation of 1-hydroxyl or 3-hydroxyl of CAP) was carried out with LC-QTOFMS and HPLC as demonstrated below. The HPLC peaks for CAP and the corresponding products are shown in Fig. 2a consistent with previous results (Liang et al., 2013). The characteristic two-chlorine-atom isotope clusters for CAP were observed with $\mathrm{m} / \mathrm{z}$ of 321,323 and $325[\mathrm{M}-\mathrm{H}]^{-}$(the $\mathrm{m} / \mathrm{z}$ of 325 showed very low abundance) (Fig. 2b). The dechlorinated amine product $\mathrm{AMCl}$ and amine product AMCl2 were identified according to the theoretical $\mathrm{m} / \mathrm{z}$ (257 and 259 [M-H] $]^{-}$one-chlorine-atom isotope clusters) and (291, 293 and $295[\mathrm{M}-\mathrm{H}]^{-}$two-chlorine-atom isotope clusters) (Fig. 2c). The curves for the four main products revealed similar trends in stages I and IV (Fig. 3a-d). The maximum AMCl yield occurred at $24 \mathrm{hr}$ for the RT-biocathode, which was markedly higher than that formed by the LT-biocathode (both closed and open circuits) (both at $p<0.001$ level, $n=18$ or $n=3$ ). Meanwhile, the AMCl2 yields (formed at $6 \mathrm{hr}$ ) between the RT- and LT-biocathode did not markedly differ. The maximum $\mathrm{AMCl}$ yield for the biocathode at $10^{\circ} \mathrm{C}(n=18)$ was significantly higher than that by the abiotic cathode at $10^{\circ} \mathrm{C}(n=3, p=0.002)$ (Fig. 3d).

$\mathrm{AMCl} 2$ and NO formation first increased and then decreased for all the modes except the LT-open-circuit biocathode mode for AMCl2 (24 hr was the time point for maximum yield). The amount of AMCl2 formed with the LT-biocathode $(n=18)$ was obviously higher than that by the abiotic cathode $(n=3)$ (Fig. 3c). It is interesting to note that no NO was formed with the open-circuit biocathode, probably owing to the abiotic cathode surface that appeared on the biocathode, which allowed for the abiotic electrochemical CAP reduction under closed circuit mode (Fig. 3a). This was different from recent results obtained using different cathode electrode materials (carbon brush in this study us. carbon cloth in a previous study) (Liang et al., 2013). In the test, the CAP-acetyl first accumulated and then was transformed in the exclusive microbial-catalyzed process (closed biocathode or open-circuit biocathode mode). More CAP-acetyl was accumulated by the open-circuit biocathode than by the closed biocathode, while the open-circuit LTbiocathode formed more CAP-acetyl than the open-circuit RT-biocathode within $24 \mathrm{hr}(n=3, p=0.014$ ) (Fig. 3b).

Microbial dehalogenation by catalyzing the cleavage of carbon-halogen bonds generally plays a key role in the detoxification of chlorinated compounds (Liang et al., 2012). The reduction of CAP to different products involved transfer of 2, 4, 6 and 8 electrons respectively for producing NO, the hydroxylamino intermediate, $\mathrm{AMCl} 2$ and $\mathrm{AMCl}$ from one CAP molecule. In this study, the biocathode dechloridation reaction generated significantly more $\mathrm{AMCl}$ than did pure microbial or electrochemical dechloridation reactions (both at $p<0.001$ level at $25^{\circ} \mathrm{C}$ and at $p<0.001$ or $p=0.002$ level, respectively, at $10^{\circ} \mathrm{C}$ ) (Fig. $3 \mathrm{~d}$ ). These observations strongly indicated that cathodophilic microbes captured more electrons from the cathode electrode for CAP reduction and the biocathode-catalyzed process can enhance CAP reduction to 

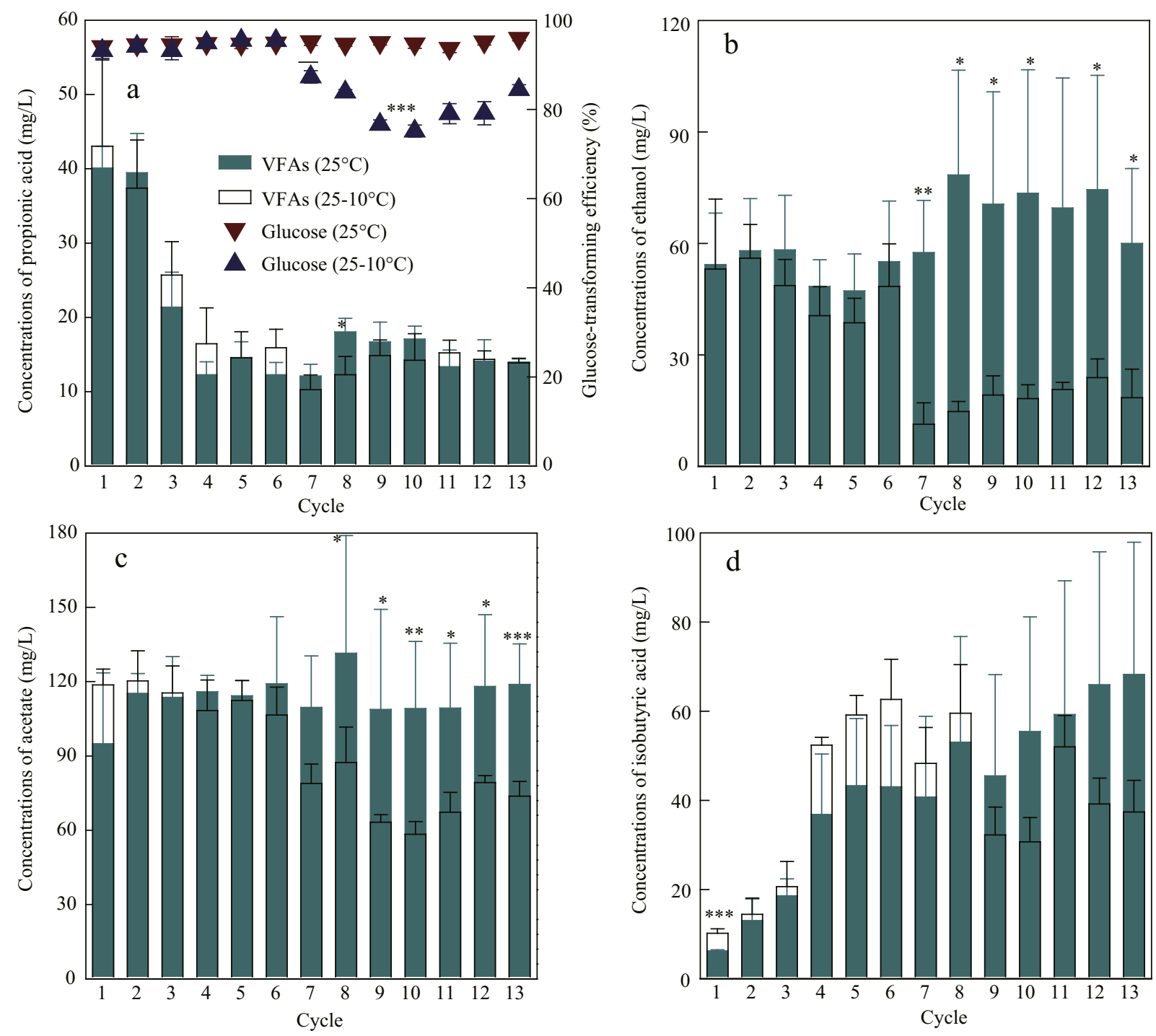

Fig. 5 - Glucose transformation, VFAs and ethanol production during biocathodic CAP degradation under different operational modes. Biocathode (1-6 cycles, both at $\left.25^{\circ} \mathrm{C}\right)$; biocathode (7-12 cycles, 25 vs. $\left.10^{\circ} \mathrm{C}\right)$ and open-circuit biocathode (13th cycle, 25 vs. $10^{\circ} \mathrm{C}$ ) was compared. The glucose transformation efficiency was calculated based on the difference between influent $(0 \mathrm{hr})$ and effluent (at $6 \mathrm{hr}$ ) glucose concentrations. The performance differences between 25 and $10^{\circ} \mathrm{C}$ were analyzed by two-tailed unpaired t-test $(n=3)$, labeled by ${ }^{* * *}$ when $p \leq 0.005,{ }^{* *}$ when $p \leq 0.01$ or ${ }^{*}$ when $p \leq 0.05$.

non-antibacterial products $\mathrm{AMCl}$ and $\mathrm{AMCl} 2$ (Liang et al., 2013; Smith et al., 2007). This study also illustrated that incorporation of the electrochemical catalytic process in the conventional anaerobic biological process can have a profound impact on the treatment of halogenated or nitroaromatic antibiotic micro-pollutants, giving products with no antibacterial activity products by a resilient and environmentally compatible biocathode BES that can cope with environments with fluctuating temperatures. Similar to the process of azo dye mineralization by incorporation of an aerobic bioreactor with the abiotic cathode/biocathode BES (breaking the azo linkage by cathodic reduction and mineralizing the produced aromatic amine by aerobic microbial catalysis) (Cui et al., 2012), this combined process would thoroughly mineralize products that are detoxified and have no antibacterial activity (AMCl2 and $\mathrm{AMCl}$ ).

\subsection{Anode potential, cathode potential and reaction current}

The electricigens of the anode biofilm were enriched by inoculating with activated sludge at $25^{\circ} \mathrm{C}$ with a $0.5 \mathrm{~V}$ voltage supply. Acetate $(1.68 \mathrm{~g} / \mathrm{L})$ and CAP $(30 \mathrm{mg} / \mathrm{L})$ served as the anode electron donor and cathode electron accepter, respectively. After $100 \mathrm{hr}$ enrichment, the anode potential reached about $-0.2 \mathrm{~V}$ (Fig. 4a). Subsequently, the cathode was inoculated with the CAP-reducing consortium five times to develop a cathode biofilm according to a previous study (Liang et al., 2013). In the start-up stage of the biocathode reactors, the reaction current of CAP reduction was decreased when the cathode electron acceptor CAP was nearly completely consumed. The cathode potential was kept at a stable level (approximately $-0.7 \mathrm{~V}$ ) during the start-up period (Fig. 4a). 


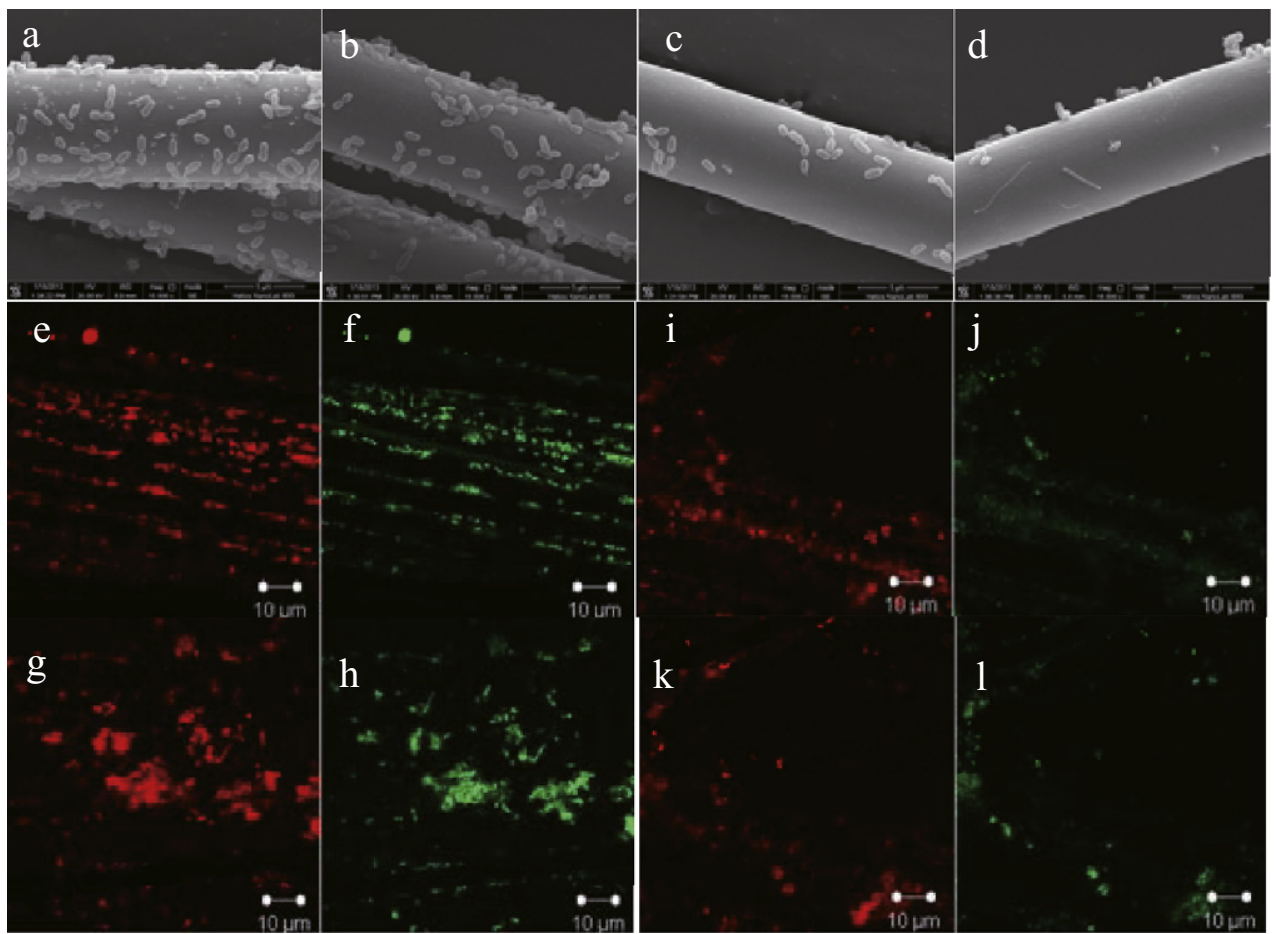

Fig. 6 - SEM (a-d) and CSLM (e-l) micrographs of cathode biofilms enriched at $10^{\circ} \mathrm{C}$ (two biological replicates: c, d, i-l) and $25^{\circ} \mathrm{C}$ (two biological replicates: a, b, e-h). Cathode biofilms were stained with SYTO 9 (green indicates active cathodophilic microbes) and propidium iodide (red notes dead cathodophilic microbes).

After six batch-fed cycles were carried out, the operational temperature for the biocathode BES was switched from 25 to $10^{\circ} \mathrm{C}$. The maximum current of CAP reduction at $10^{\circ} \mathrm{C}$ $(0.31 \pm 0.08 \mathrm{~mA})$ was lower than that at $25^{\circ} \mathrm{C}(0.52 \pm 0.06 \mathrm{~mA})$ $(p<0.001)$. This occurrence should be attributable to the ability of the cathodophilic microbes in the biofilm to adapt to the applied temperature. Conversely, the same bioreactor group before temperature switchover had higher cathode current $(p=0.045)$ (Fig. 4b). These results indicated that low temperature stress decreased the activity of biocathodic CAP degradation. Although the anodophilic communities were enriched at $25^{\circ} \mathrm{C}$, the current-producing performance was not affected at $10^{\circ} \mathrm{C}$, which was different from the results of a recent study (Liu et al., 2013).
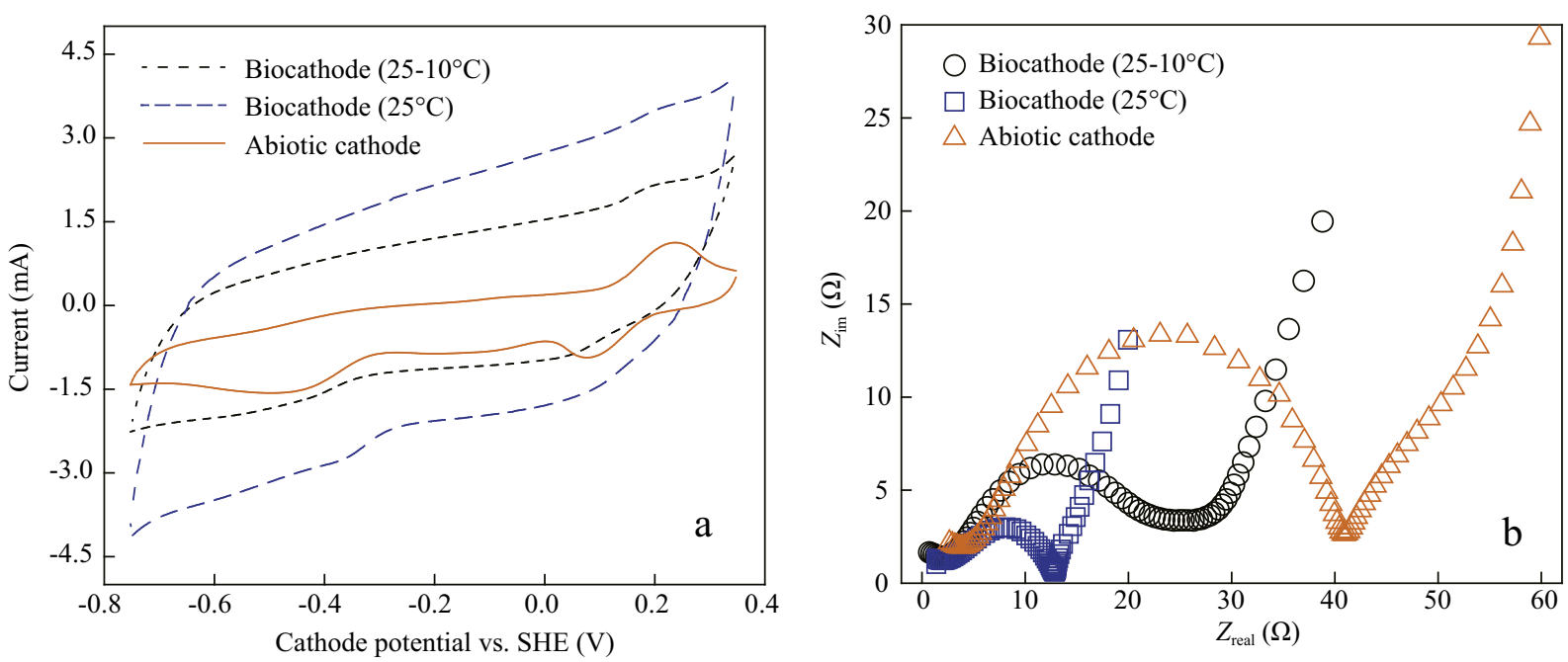

Fig. 7 - Cyclic voltammograms of the biocathode $\left(10\right.$ and $\left.25^{\circ} \mathrm{C}\right)$ and abiotic cathode (a). Nyquist plots of the biocathode $(10$ and $25^{\circ} \mathrm{C}$ ) and abiotic cathode (b). 


\subsection{Biocathodic glucose transformation}

Microbial transformation of glucose (which served as the intracellular electron donor and growth carbon source for cathodophilic microbes) releases electrons, which could be used by cathodophilic microbes for the enhancement of CAP and nitrobenzene reduction (Liang et al., 2013; Sun et al., 2013; Wang et al., 2011). At $25^{\circ} \mathrm{C}$, the biocathode reactors (divided into two groups) had the same trends for the efficiencies of glucose transformation and VFA as well as ethanol production (1-6 cycles in Fig. 5). Acetate was the main product in the glucose fermentation, followed by ethanol, isobutyric acid and propionic acid. When switching the operational temperature from 25 to $10^{\circ} \mathrm{C}$, the acetate and ethanol yield of the LTbiocathode was decreased, which was consistent with the marked decrease in the glucose fermentation ability (7-13 cycles in Fig. $5 \mathrm{a}-\mathrm{c}$ ). The decreased activity of glucose metabolism by cathodophilic microbes at $10^{\circ} \mathrm{C}$ weakened the supply of intracellular electrons, aside from the extracellular electrons from the electrode to reduce CAP. The yields of propionic acid (except for cycle $8, p=0.031$ ) and isobutyric acid were not significantly changed (7-13 cycles in Fig. 5a and d).

\subsection{Microbial role in the biocathodic CAP degradation}

SEM photos of cathode biofilms revealed that populations of cathodophilic microbes declined with decreasing temperature (two biological replicates) (Fig. 6a-d). The live/dead staining CLSM analysis indicated that the RT-biocathode (Fig. 6e-h) had more attached cells than the LT-biocathode (Fig. 6i-l), correlating with the SEM results. The presence of electrochemically active microbes attached on the cathode at $10^{\circ} \mathrm{C}$ should explain why the LT-biocathode mode had significantly higher $\mathrm{AMCl}$ yield and $k_{\mathrm{CAP}}$ than the abiotic cathode mode.

The CV tests showed that the RT-biocathode had the highest CAP reduction reaction current among the three operational modes. Decrease in operational temperature from 25 to $10^{\circ} \mathrm{C}$ apparently reduced the cathode current, but the value was still higher than that of the abiotic cathode. CV analysis highlighted the higher peak current and lower over-potential for CAP reduction obtained with the biocathode compared with those for the abiotic cathode (Fig. 7a). This observation suggested that the cathode-attached microbes were involved in the electron transfer to CAP reduction, possibly via a direct (e.g., outer membrane c-type cytochromes) or indirect electron transfer mechanism (e.g., microbial produced mediators or periplasmic c-type cytochromes and hydrogenase networks) (Rosenbaum et al., 2011). However, these proposed electron transfer mechanisms within the complex biocathode microbial community need further investigation by functional metagenomics, metatranscriptomics and metaproteomics approaches. Restated, the CV tests confirmed the role of microbes on the biocathode on the noted CAP reduction activity.

EIS experiments were conducted to investigate the polarization resistance of electron transfer by the abiotic cathode, RT-biocathode and LT-biocathode, and the Nyquist plots of the three modes were fitted to the equivalent circuits (Fig. 7b). The polarization resistances for the RT-biocathode $(9.6 \Omega)$ or LT-biocathode $(22.3 \Omega)$ were lower than that for the abiotic cathode $(36.4 \Omega$ ) (Fig. 7b). This finding demonstrated that attached growth of cathodophilic microbes would significantly enhance the rate of electron transfer for the biocathodic CAP reduction. Collectively, the CV, EIS, SEM and CSLM results suggested that the low polarization resistance and high cathode reaction current for the biocathode were attributable to the attached microbial growth on the cathode electrode. These tests also confirmed that electrochemically active cathodophilic microbes on the cathode significantly accelerated the electron transfer rate for the enhancement of biocathodic CAP degradation.

\section{Conclusions}

Biocathode-catalyzed activity for CAP degradation was obviously decreased when the temperature dropped by $15^{\circ} \mathrm{C}$, while the biocathode BES had significantly higher $k_{\mathrm{CAP}}$, nitro-group reduction and dechloridation efficiency compared with those of the abiotic cathode BES. Electrochemically active cathodophilic microbes on the cathode lowered polarization resistance and over-potentials and finally accelerated the electron transfer rate for the biocathodic CAP degradation in the BES. CAP was efficiently degraded by the biocathode BES under large temperature switchover. Such a resilient and efficient process has potential use in CAP-containing wastewater treatment.

\section{Acknowledgments}

This work was supported by the National Science Foundation for Distinguished Young Scholars of China (No. 51225802), the National Natural Science Foundation of China (No. 51178140), the National Creative Research Groups Project (No. 51121062), the State Key Laboratory of Urban Water Resource and Environment of HIT (No. 2013DX02) and the Hundred Talents Program of the Chinese Academy of Sciences (No. 29BR2013001).

\section{R E F E R E N C E S}

Andam, C.P., Fournier, G.P., Gogarten, J.P., 2011. Multilevel populations and the evolution of antibiotic resistance through horizontal gene transfer. FEMS Microbiol. Rev. 35 (5), 756-767.

Cui, D., Guo, Y.Q., Cheng, H.Y., Liang, B., Kong, F.Y., Lee, H.S., et al., 2012. Azo dye removal in a membrane-free up-flow biocatalyzed electrolysis reactor coupled with an aerobic bio-contact oxidation reactor. J. Hazard. Mater. 239-240, 257-264.

Davies, J., Davies, D., 2010. Origins and evolution of antibiotic resistance. Microbiol. Mol. Biol. Rev. 74 (3), 417-433.

Feder, H.M., Osier, C., Maderazo, E.G., 1981. Chloramphenicol - a review of its use in clinical-practice. Rev. Infect. Dis. 3 (3), 479-491.

Herbert, D., Philipps, P.J., Strange, R.E., 1971. Carbohydrate analysis. Methods Enzymol. 5, 265-277.

Huang, L.P., Cheng, S.A., Chen, G.H., 2011. Bioelectrochemical systems for efficient recalcitrant wastes treatment. J. Chem. Technol. Biotechnol. 86 (4), 481-491.

Kong, F.Y., Wang, A.J., Liang, B., Liu, W.Z., Cheng, H.Y., 2013. Improved azo dye decolorization in a modified sleeve-type bioelectrochemical system. Bioresour. Technol. 143, 669-673. 
Le-Minh, N., Khan, S.J., Drewes, J.E., Stuetz, R.M., 2010. Fate of antibiotics during municipal water recycling treatment processes. Water Res. 44 (15), 4295-4323.

Lettinga, G., Rebac, S., Zeeman, G., 2001. Challenge of psychrophilic anaerobic wastewater treatment. Trends Biotechnol. 19 (9), 363-370.

Leung, H.W., Minh, T.B., Murphy, M.B., Lam, J.C., So, M.K., Martin, M., et al., 2012. Distribution, fate and risk assessment of antibiotics in sewage treatment plants in Hong Kong, South China. Environ. Int. 42 (SI), 1-9.

Li, J., Liu, G.L., Zhang, R.D., Luo, Y., Zhang, C.P., Li, M.C., 2010. Electricity generation by two types of microbial fuel cells using nitrobenzene as the anodic or cathodic reactants. Bioresour. Technol. 101 (11), 4013-4020.

Li, J., Shao, B., Shen, J.Z., Wang, S.C., Wu, Y.N., 2013. Occurrence of chloramphenicol-resistance genes as environmental pollutants from swine feedlots. Environ. Sci. Technol. 47 (6), 2892-2897.

Liang, B., Jiang, J.D., Zhang, J., Zhao, Y.F., Li, S.P., 2012. Horizontal transfer of dehalogenase genes involved in the catalysis of chlorinated compounds: evidence and ecological role. Crit. Rev. Microbiol. 38 (2), 95-110.

Liang, B., Cheng, H.Y., Kong, D.Y., Gao, S.H., Sun, F., Cui, D., et al., 2013. Accelerated reduction of chlorinated nitroaromatic antibiotic chloramphenicol by biocathode. Environ. Sci. Technol. 47 (10), 5353-5361.

Liang, B., Cheng, H.Y., Van Nostrand, J.D., Ma, J., Yu, H., Kong, D.Y., et al., 2014. Microbial community structure and function of nitrobenzene reduction biocathode in response to carbon source switchover. Water Res. 54, 137-148.

Liu, L.H., Tsyganova, O., Lee, D.J., Su, A., Chang, J.S., Wang, A.J., et al., 2012a. Anodic biofilm in single-chamber microbial fuel cells cultivated under different temperatures. Int. J. Hydrogen Energy 37 (20), 15792-15800.

Liu, W.Z., Huang, S.C., Zhou, A.J., Zhou, G.Y., Ren, N.Q., Wang, A.J., et al., 2012b. Hydrogen generation in microbial electrolysis cell feeding with fermentation liquid of waste activated sludge. Int. J. Hydrogen Energy 37 (18), 13859-13864.

Liu, L.H., Tsyganova, O., Lee, D.J., Chang, J.S., Wang, A.J., Ren, N.Q., 2013. Double-chamber microbial fuel cells started up under room and low temperatures. Int. J. Hydrogen Energy 38 (35), 15574-15579.

Lu, L., Ren, N.Q., Zhao, X., Wang, H.A., Wu, D., Xing, D.F., 2011. Hydrogen production, methanogen inhibition and microbial community structures in psychrophilic single-chamber microbial electrolysis cells. Energy Environ. Sci. 4 (4), 1329-1336.

Lu, L., Xing, D.F., Ren, N.Q., 2012. Bioreactor performance and quantitative analysis of methanogenic and bacterial community dynamics in microbial electrolysis cells during large temperature fluctuations. Environ. Sci. Technol. 46 (12), 6874-6881.

Martelli, A., Mattioli, F., Pastorino, G., Robbiano, L., Allavena, A., Brambilla, G., 1991. Genotoxicity testing of chloramphenicol in rodent and human-cells. Mutat. Res. 260 (1), 65-72.

Michie, I.S., Kim, J.R., Dinsdale, R.M., Guwyb, A.J., Premier, G.C., 2011. The influence of psychrophilic and mesophilic start-up temperature on microbial fuel cell system performance. Energy Environ. Sci. 4 (3), 1011-1019.

Mu, Y., Rozendal, R.A., Rabaey, K., Keller, J., 2009. Nitrobenzene removal in bioelectrochemical systems. Environ. Sci. Technol. 43 (22), 8690-8695

Parsley, L.C., Consuegra, E.J., Kakirde, K.S., Land, A.M., Harper, W.F., Liles, M.R., 2010. Identification of diverse antimicrobial resistance determinants carried on bacterial, plasmid, or viral metagenomes from an activated sludge microbial assemblage. Appl. Environ. Microbiol. 76 (11), 3753-3757.

Rosenbaum, M., Aulenta, F., Villano, M., Angenent, L.T., 2011. Cathodes as electron donors for microbial metabolism: which extracellular electron transfer mechanisms are involved? Bioresour. Technol. 102 (1), 324-333.

Shen, J.Y., Feng, C.C., Zhang, Y.Y., Jia, F., Sun, X.Y., Li, J.S., et al., 2012. Bioelectrochemical system for recalcitrant p-nitrophenol removal. J. Hazard. Mater. 209, 516-519.

Smith, A.L., Erwin, A.L., Kline, T., Unrath, W.C.T., Nelson, K., Weber, A., et al., 2007. Chloramphenicol is a substrate for a novel nitroreductase pathway in Haemophilus influenzae. Antimicrob. Agents Chemother. 51 (8), 2820-2829.

Sun, M., Reible, D.D., Lowry, G.V., Gregory, K.B., 2012. Effect of applied voltage, initial concentration, and natural organic matter on sequential reduction/oxidation of nitrobenzene by graphite electrodes. Environ. Sci. Technol. 46 (11), 6174-6181.

Sun, F., Liu, H., Liang, B., Song, R., Yan, Q., Wang, A., 2013. Reductive degradation of chloramphenicol using bioelectrochemical system (BES): a comparative study of abiotic cathode and biocathode. Bioresour. Technol. 143, 699-702.

Wang, A.J., Cheng, H.Y., Liang, B., Ren, N.Q., Cui, D., Lin, N., et al., 2011. Efficient reduction of nitrobenzene to aniline with a biocatalyzed cathode. Environ. Sci. Technol. 45 (23), 10186-10193.

Wang, A.J., Cui, D., Cheng, H.Y., Guo, Y.Q., Kong, F.Y., Ren, N.Q., et al., 2012. A membrane-free, continuously feeding, single chamber up-flow biocatalyzed electrolysis reactor for nitrobenzene reduction. J. Hazard. Mater. 199, 401-409.

Wang, Y.Z., Wang, A.J., Liu, W.Z., Sun, Q., 2013. Enhanced azo dye removal through anode biofilm acclimation to toxicity in single-chamber biocatalyzed electrolysis system. Bioresour. Technol. 142, 688-692.

Xi, C., Zhang, Y., Marrs, C.F., Ye, W., Simon, C., Foxman, B., et al., 2009. Prevalence of antibiotic resistance in drinking water treatment and distribution systems. Appl. Environ. Microbiol. 75 (17), 5714-5718.

Xie, G.J., Liu, B.F., Ding, J., Ren, H.Y., Xing, D.F., Ren, N.Q., 2011. Hydrogen production by photo-fermentative bacteria immobilized on fluidized bio-carrier. Int. J. Hydrogen Energy 36 (21), 13991-13996.

Zhang, T., Li, B., 2011. Occurrence, transformation, and fate of antibiotics in municipal wastewater treatment plants. Crit. Rev. Environ. Sci. Technol. 41 (11), 951-998.

Zhang, X.X., Zhang, T., Fang, H.H.P., 2009. Antibiotic resistance genes in water environment. Appl. Microbiol. Biotechnol. 82 (3), 397-414. 